\title{
EXPERIMENTAL MEASUREMENT OF INTERNAL TEMPERATURE OF A TUBE IN COOLING ON A BED OF PASSAGECONTINUOUS UNDER NATURAL CONVECTION
}

\author{
J. L. F. Souza ${ }^{\mathrm{a}}$, \\ M. Ziviani ${ }^{\mathbf{b}}$, \\ J. F. A. Vitor ${ }^{\mathrm{a}}$, \\ F. A. R. Filho ${ }^{a}$, \\ and R. O. Nunes \\ ${ }^{a}$ Centro Federal de Educação Tecnológica de \\ Minas Gerais, CEFET-MG, Brasil \\ Departamento de Engenharia Mecânica \\ jleonciofs@gmail.com \\ jfavitor@gmail.com \\ 77frodrigues@gmail.com \\ ${ }^{\mathrm{b}}$ Universidade Federal de Minas Gerais, \\ UFMG - MG, Brasil \\ Departamento de Engenharia Mecânica \\ ziviani@demec.ufmg.br \\ rphnunes@demec.ufmg.br \\ Received: September 12, 2018 \\ Revised: October 18, 2018 \\ Accepted: February 18, 2019
}

\section{ABSTRACT}

The process behind manufacturing bars and profiles in the steel industry utilizes heating and cooling at controlled rates in order to facilitate changes in their geometries, as well as to obtain desired changes in mechanical steel properties.This work develops an experimental procedure to reproduce the thermal behavior tubes over a cooling bed. In literature the experimental results obtained by Damasceno (2004) do not take into account the temperature measurements of the sidewalls and the floor below the bed and storage temperatures within and outside the shed. These failures compromise the claim to validate the mathematical model of Souza (2015) and therefore new measurements were obtained with room temperatures controlled, order to validate the mathematical model of a cooling bed heat treatment of steel mill Vallourec Tubes, located in Belo Horizonte, Brazil.

Keywords: cooling bed; thermal treatment; heat transfer, experimental measurement; natural convection

\section{NOMENCLATURE}

$\mathrm{u}_{\mathrm{t}} \quad$ expanded uncertainty

$\mathrm{u}_{\mathrm{c}} \quad$ combined standard uncertainty

\section{INTRODUCTION}

Processes for the bars manufacture and rods in the steel industry use heat to facilitating geometrical transformations as well as to obtain changes in the mechanical properties of the steel. The heating, followed by cooling, aims to reach the intended objectives. The production of steel bars and profiles uses heat treatment as a fundamental step to achieve certain mechanical properties. For example, the heat treatment of quenching and tempering are typically used in the manufacturing of bars and rods to use in the automotive, petrochemical, shipbuilding, and aerospace industries - as well as in boilers, bearings and many other applications. According to Hashmi (2006), metal tube manufacturing methods can be broadly divided into (a) seamless and (b) welded, and in external diameters from a few meters to a few nanometers.

The cooling load (profiling, circular or rectangular bar, etc.) involves radiation and either natural or forced convection over large beds. The transport of the charge through the bed occurs due to the motion of moving parts and some portions of the bed, which originates from the influence of gravity. The load speed in the bed is responsible for controlling the cooling rate. There are various types of beds for the most diverse applications, and the most common ones include:

- A horizontal bed with one cooling region. Its mechanical system with flowing rollers is activated by gear capable of rotating the load, with or without the presence of fans below the bed rails;

- A horizontal bed with one or more cooling regions consisting of fixed and mobile beams for load movement in vertical and horizontal directions, with or without the presence of fans below the bed rails.

The most common situations found in steel mills, in relation to load shifting in the bed, are:

- A load (circular bar) that moves along the bed at the same time that is rotated around its own axis; 
- A load that is placed in a walking beam furnace consisting of fixed and mobile beams; in this casse, the load displacement takes place by through means of these movable beams.

To better understand the operation of a cooling bed, the description of the bed of the tempering process Vallourec Steel Company will be shown below. The cooling bed has two parts: bed I characterized by forced convection due to the presence of fans, and bed II characterized by natural convection.

The bed shown schematically in Figure 1 has bed I (19.27m long, $12.65 \mathrm{~m}$ wide and $1.63 \mathrm{~m}$ high) and bed II $(19.27 \mathrm{~m}$ long, $12.65 \mathrm{~m}$ wide and 3.33mhigh). At a certain instance, Bed Procedure I can sustain up to twice the amount of Bed II tubes by adjusting the velocity of the roller chain in bed I to twice the current velocity in bed II.

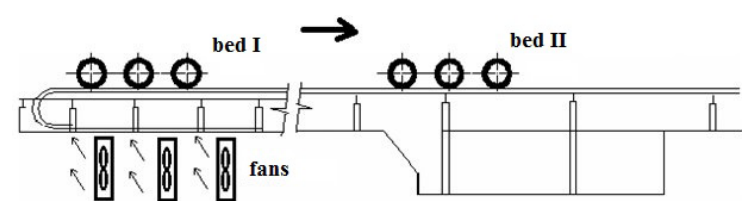

Figure 1. Illustration of the cooling bed layout.

The heat and temperature estimation are key points for optimizing thermal processes. Davies et al. (2007) performed a review measurement process in the thermal area, where it was concluded that the main issue entailed having solely one measurement point which insufficiently represents the heat flow. Therefore, in order to measure thermal field equipment and products, it may be necessary to develop a complex configuration using various thermocouples. IR Thermography is another way to measure the temperature, allowing the ability to directly measure the entire field in the area of interest with a high spatial and temporal resolution.

Several experimental studies in the thermal area have been published in the literature. Shabanian et al. (2011) presented experiment results and Computational Fluid Dynamics (CFD) modeling studies on heat transfer, friction factor and thermal performance of an air-cooled heat exchanger equipped with three types of tube inserts, including butterfly, classic and jagged twisted tape. In the studied range of Reynolds number, the maximum thermal performance factor was obtained by the butterfly insert with an inclined angle of $90^{\circ}$. The results have also revealed that the difference between the heat transfer rates obtained from employing the classic and jagged inserts reduces by decreasing the twist ratio. The predicted results for CFD were used to explain the observed results in terms of turbulence intensity. In addition, good agreements between the predicted and measured Nulsset number as well as friction factor values were obtained.

Shen et al. (2014) presented experimental results by thermocouples attached to the inner wall of the tube. The temperature measurements were made along the tube in axial and angular directions.

Lin et al. (2012) studied a simple correlation with acceptable engineering accuracy which was proposed to estimate the bulk temperature from the measured wall temperature in laminar tube flow. In this correlation, five measurable parameters should be prior known.

Yoon et al. (2008) presented an experiment results of the heat and mass transfer characteristics of a water-LiBr horizontal tube absorber made of small diameter tubes. The experimental set up includes a tube absorber, a generator, solution distribution system and cooling water system. The experimental results show that the heat and mass transfer performance of the absorber increases as the tube diameter decreases.

By way of illustration of the heat conduction within pipes, Dixon et al. (2012) employed CFD simulations of heat transfer in fixed beds of spheres which were validated by comparison to experimental measurements in a pilot-scale rig. The comparisons were made for particle Reynolds numbers in the range $2200<\mathrm{Re}<27000$ for tube-to-particle diameter ratio $\mathrm{N}=5.45$, and in the range $1600<\mathrm{Re}$ $<5600$ for $\mathrm{N}=7.44$. Radial temperature profiles were obtained at four axial positions in the heated bed spaced $0.16 \mathrm{~m}$ apart.

Zhao and Jiang, (2011) studied the fluid R134a. The in-tube cooling flow and heat transfer characteristics of R134a at supercritical pressures are measured experimentally for various pressures and mass fluxes in a horizontal tube. The test section wall temperatures were measured by T-type thermocouples welded onto the outside surface of the tube. The cooling fluid inlet and outlet temperatures were measured by sheathed thermocouples.

$\mathrm{Hu}$ et al. (2009) constructed an experimental apparatus composed of multiple oscillating tubes to measure the temperature distribution of the wall. Then, a numerical simulation is developed in order to allow the analysis of this heat transfer process within the oscillating tube.

Abdulkadir (2015) presents a comparison of the results obtained from experiments and CFD studies of slug flowin a vertical riser. The simulation results were validated both qualitatively and quantitatively against experimental data. A reasonably good agreement was observed between the results of the experiment and CFD.

Roberts et al. (2011) studied experimental results with established empirical relationships to estimate losses due to radiation in an annular heat exchanger at temperatures up to $950^{\circ} \mathrm{C}$.

Rezvantalab et al. (2011) studied laminar free convection heat transfer from two vertical arrays of five isothermal cylinders separated by flow diverters is studied experimentally using a Mach-Zehnder interferometer. The effect ratio of the horizontal 
spacing between two cylinder arrays to their diameter on heat transfer from the cylinders is investigated for various Rayleigh numbers.

Laminar natural convection heat transfer from a vertical array of horizontal isothermal elliptic cylinders with a vertical major axis has been experimentally investigated by Yousefi and Ashjaee (2007). Experiments were carried out using a MachZehnder interferometer with the cylinder spacing from two to five cylinder along the major axes and at Rayleigh numbers in the range of $10^{3}$ and $2.5 \times 10^{3}$.

Agrawal et al. (2012) studied the transient cooling of a hot surface. The transient cooling performance of the test surface was determined on the basis of rewetting temperature, wetting delay and the rewetting velocity. The correlations were developed to evaluate the stagnation and the local Nusselt number for the steady state cooling condition.

An experimental study of heat transfer during quenching of a cylindrical stainless-steel test specimen has been performed by Karwa et al. (2011). A sub cooled water jet is directed onto the upward facing flat face of the cylinder. The test specimen is heated to an initial temperature slightly above $900^{\circ} \mathrm{C}$ and then quenched. The authors concluded that the jet impingement quenching process is different from a flow boiling process due to the steep variation in heat transfer distribution on the surface.

The aim of this paper is to present the experimental methodology used to study the cooling process of a steel pipe in a section of the cooling bed without forced convection (bed II), in order to obtain the temperature profile over time. Therefore, experimental measurements of the tube and the environment were carried out in a continuous bed belonging to the Vallourec steel company of Belo Horizonte, Minas Gerais (Fig. 1), after heat treatment of tempering.

\section{EXPERIMENTAL SETUP AND PROCEDURE}

In steelmaking, the measurements of temperatures are mostly carried out by thermocouples. The operating principle consists of an electrical device made up of two different conductors forming electrical junctions at different temperatures. A thermocouple produces a temperature-dependent voltage as a result of the thermoelectric effect, and this voltage can be interpreted to measure temperature.

The measurement of temperatures during the cooling was performed with the data acquisition system Datapaq, a system made of two data collectors, each with eight channels and a storage capacity of 16,000 points. The measured values were then downloaded into a Microsoft Excel spreadsheet. The Type $\mathrm{K}$ thermocouples were used (chromelalumel) of $1.50 \mathrm{~mm}$ diameter with mineral insulating composite magnesium oxide, positioned at six points on the inner surface of the test tube.Type $\mathrm{K}$ thermocouples (chromel-alumel) were used with a diameter of $1.50 \mathrm{~mm}$ with mineral insulating composite magnesium oxide, positioned at six points on the inner surface of the test tube.

The experiment was carried out during normal production of heat treatment line of Vallourec Tubes, lasting 2:32 hours. For the experimental data survey, a tube was chosen with the dimensions $323.9 \mathrm{~mm}$ in diameter, $25.4 \mathrm{~mm}$ in thickness and $9300 \mathrm{~mm}$ in length. Figure 2 schematically shows the test tube and the elements present around the continuous bed. Careful determination of such elements around the pipe is required for calculating the radiation employed in the validation of the mathematical model proposed by Souza (2015).

For obtaining temperatures in some parts of the tube, a device was built to maintain contact among six thermocouples within its inner wall. The placement of the thermocouples inside the tube was done to reach three axial positions at the extremities and center of the tube. Figure 3 shows the assembly scheme of the thermocouples in the test tube, and Figure 4 displays the front view of the measuring system of the test tube temperature in the bed II.

Before entering tube in the bed II, thermocouples were connected in Datapaq channels and six thermocouples were placed inside the tube. Thereafter, the tube movement was accompanied by an operator that moved Datapaq and wired thermocouples in order to avoid disconnecting during the experiment.

Although care has been taken in obtaining the measure of the temperature of the inner wall of the tube, some arrangements were necessary to carry out with the cooling bed in full production. The mounting of the main shaft to direct the six thermocouples in the test tube was performed at end of the cooling bed with forced convection (bed I, Fig.1) and measurements were taken every 15 seconds by Datapaq, considering only the measurements on the cooling bed without forced convection (bed II, Fig 1).Although the device leads the six thermocouples to the inner wall of the tube, it does not guarantee that all points will always remain in contact. In fact, it is impossible to ensure constant contact of the thermocouple with the inner wall of the test tube. With this in consideration, it was then decided to record the maximum temperature measured during each 975 s interval until the end of experimentation time. Once the maximum temperature is that which best describes the moment of actual contact between the thermocouple and the inner wall of the tube.

It is impossible to ensure constant contact of the thermocouple with the inner wall of the test tube; it was then chosen to record the maximum temperature measured during each $975 \mathrm{~s}$ interval until the end of experimentation time. Once the maximum temperature is that which best describes the moment 
of actual contact between the thermocouple and the inner wall of the tube.

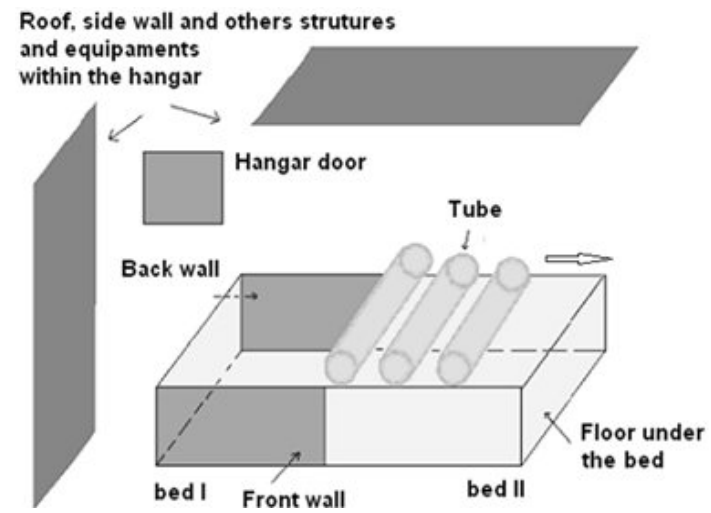

Figure 2. The tube and other surfaces.

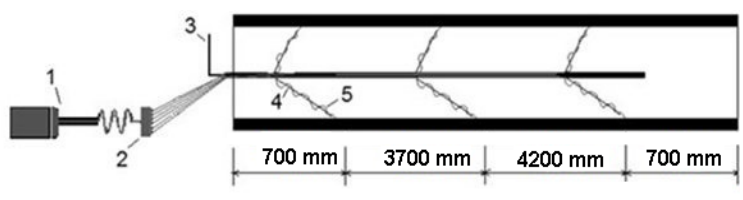

1 - Data acquisition system (Datapaq)

2 - Thermocouples fitting at Datapaq

3 - Main stem to drive thermocouples

4 - Secondary shaft to drive thermocouple

5 - Thermocouple

6 - Contact position at cross section

Figure 3. Placement of the thermocouples in the test tube.

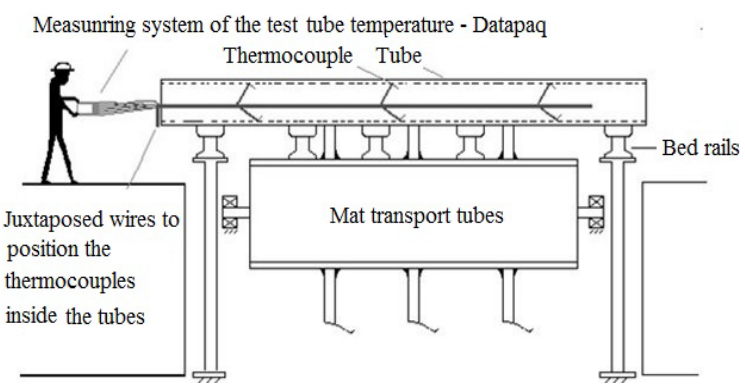

Figure 4. Front view of the temperature measurement system of the tube test.

The temperature measurement was carried out using a digital thermohygrometer with $0.1^{\circ} \mathrm{C}$ of resolution. Measurements were performed in reverse order and closed the entrance of the shed heat treatment regions. The temperature measurement was also obtained at the entrance of the heat treatment shed. Figure 5 shows the positions where the ambient air temperature was obtained.

The ground temperature measurement below bed II was performed using a digital pyrometer with a $0.1^{\circ} \mathrm{C}$ resolution. This device is set to temperature measurement, considering an emissivity of 0.9 as indicated in Souza (2015).

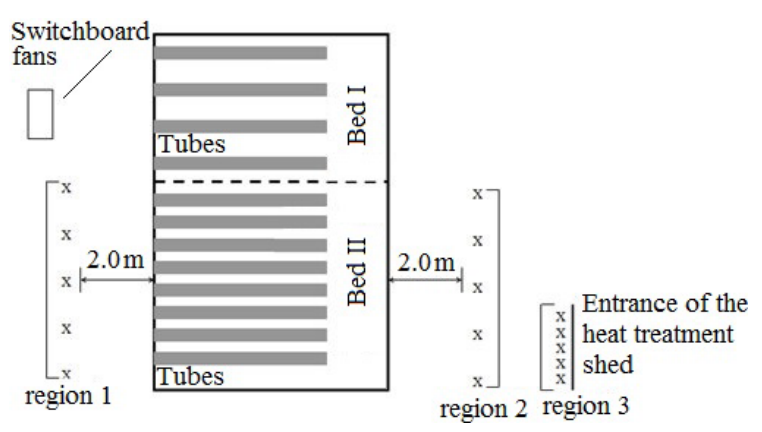

Figure 5. Room temperature measurement system, where $\mathrm{X}$ indicates the measurement points.

\section{UNCERTAINTY ANALYSIS}

Measurement uncertainty allows the determination of a range in which the true value of the quantity is measured. The following sections show the calculations of the uncertainties in this study.

\section{Uncertainty of Tube Temperature Measurement}

- Uncertainty related to temperature measurement position: $\pm 5.0{ }^{\circ} \mathrm{C}$.

The measurement system using Datapaq with type $\mathrm{K}$ thermocouples has the following sources of uncertainty:

- $\quad$ Transducer Uncertainty (data collector $)= \pm 1.0^{\circ} \mathrm{C}$;

- Sensor Uncertainty (type K thermocouple) $= \pm 1.0$ ${ }^{\circ} \mathrm{C}$ or $\pm 0.75 \%$ of the measurement value, whichever is greater.

As the maximum temperature measured is $143.5^{\circ} \mathrm{C}$, the combined standard uncertainty, $u_{c}$, is:

$$
u_{c}= \pm \sqrt{(5.0)^{2}+(1.0)^{2}+(1.1)^{2}}= \pm 5.2^{\circ} C
$$

The combined standard uncertainty $\left(u_{c}\right)$ is multiplied by a coverage factor to obtain the expanded uncertainty $\left(u_{t}\right)$. Depending on the experiment's repeated inability has not been possible using the sources of Uncertainty Type A. These uncertainties include the standard deviation of a series of measurements. In such cases the literature Figliola and Beasley (2015) recommend a coverage factor 2.0 at the $95 \%$ confidence level. Therefore, the expanded uncertainty is:

$$
u_{t}=2.0 \times u_{c}= \pm 10.4{ }^{\circ} \mathrm{C}
$$

\section{Uncertainty of Ambient Air Temperature Measurement}

The measurement system using the digital thermohygrometer has the following sources of uncertainty: 
- $\quad$ Sample standard deviation associated with the repetitiveness of measurements: $\pm 0.5^{\circ} \mathrm{C}$ in Region 1, $\pm 0.3^{\circ} \mathrm{C}$ Region 2 and $\pm 0.3^{\circ} \mathrm{C}$ in Region 3 as it is shown in Figure 5;

- Uncertainty associated to the instrument resolution: $\pm 0.1^{\circ} \mathrm{C}$;

- Uncertainty associated with instrument calibration: $\pm 0.1^{\circ} \mathrm{C}$.

The combined standard uncertainty of the ambient air temperature in Regions 1, 2 and 3 indicated in Figure 5 are respectively:

$$
\begin{aligned}
& u_{c}= \pm \sqrt{(0.5)^{2}+\sqrt{(0.1)^{2}+(0.1)^{2}}}= \pm 0.52^{\circ} \mathrm{C} \\
& u_{c}= \pm \sqrt{(0.3)^{2}+\sqrt{(0.1)^{2}+(0.1)^{2}}}= \pm 0.33^{\circ} \mathrm{C} \\
& u_{c}= \pm \sqrt{(0.3)^{2}+\sqrt{0.1)^{2}+(0.1)^{2}}}= \pm 0.33^{\circ} \mathrm{C}
\end{aligned}
$$

The average, the expanded uncertainty and the coverage factor at the $95 \%$ confidence level are shown in Tab. 1.

Table 1. Average, coverage factor and expanded uncertainty to ambient air temperature.

\begin{tabular}{|c|c|c|c|}
\hline $\begin{array}{c}\text { The region } \\
\text { indicated } \\
\text { in the Fig. 5. }\end{array}$ & $\begin{array}{c}\text { Average of five } \\
\text { measurements } \\
\left({ }^{\circ} \mathrm{C}\right)\end{array}$ & $\begin{array}{c}\text { Cover age } \\
\text { factor }\end{array}$ & $\begin{array}{c}\text { Expanded } \\
\text { uncertainty } \\
\left({ }^{\circ} \mathrm{C}\right)\end{array}$ \\
\hline 1 & 37.0 & 2.72 & \pm 1.4 \\
\hline 2 & 36.0 & 2.54 & \pm 0.8 \\
\hline 3 & 30.0 & 2.54 & \pm 0.8 \\
\hline
\end{tabular}

The measurement system using digital pyrometer has the following sources of uncertainty:

- Sample standard deviation due to repeatability of measurements: $\pm 1.9^{\circ} \mathrm{C}$;

- Uncertainty due to the resolution of the instrument: $\pm 0.1^{\circ} \mathrm{C}$.

The combined standard uncertainty of the ground temperature is:

$$
u_{c}= \pm \sqrt{(1.9)^{2}+(0.1)^{2}}= \pm 1.9^{\circ} C
$$

The average, the expanded uncertainty and the coverage factor at the $95 \%$ confidence level are shown in Tab. 2.

Table 2. Average, expanded uncertainty and coverage factor for floor temperature.

\begin{tabular}{|c|c|c|c|}
\hline Region & $\begin{array}{c}\text { Average of five } \\
\text { measurements }\left({ }^{\circ} \mathrm{C}\right)\end{array}$ & Coverage factor & $\begin{array}{c}\text { Expanded } \\
\text { uncertainty }\left({ }^{\circ} \mathrm{C}\right)\end{array}$ \\
\hline $\begin{array}{c}\text { Ground } \\
\text { below the } \\
\text { bed II }\end{array}$ & 46.4 & 2.87 & \pm 5.5 \\
\hline
\end{tabular}

\section{RESULTS AND DISCUSSION}

The experimental results presented by Damascene (2004) do not incorporate temperature measurement of the side walls and the floor below the bed and storage temperatures within and outside the shed. Thus, the objective of this work was to generate experimental data without the influence of fans. It was performed using tube temperature measurement through the same cooling bed, but only in the second part of the bed, compelling experimenters to consider the influence of natural convection The temperature measurements were made using a test tube with $323.9 \mathrm{~mm}$ in diameter, $25.4 \mathrm{~mm}$ in thickness and $9.30 \mathrm{~m}$ in length. Figure 6, Position 1 is in the end opposite to the shed entrance, while Position 3 is in the proximal end of the entry.

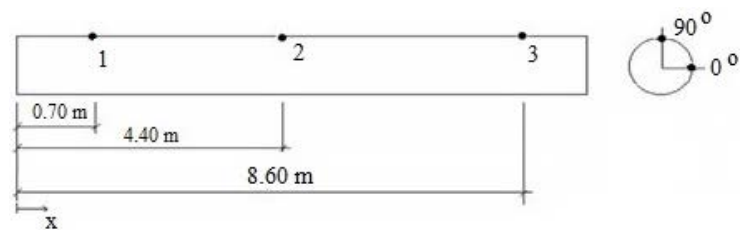

Figure 6. Measurement points distributed along the test tube.

To obtain the temperature in the tube along the cooling bed, a device was capable of holding six thermocouples in contact with its inner wall, as described above. The placement of thermocouples in the tube consisted of three positions in the axial direction: in the ends, center, and two angular positions according to Figure 6. Temperature measurement during the cooling was performed with the data acquisition system Datapaq. This system comprises two data collectors, each one with eight channels and a storage capacity of 16,000 points. Type $\mathrm{K}$ thermocouples (chromel-alumel) $1.50 \mathrm{~mm}$ in diameter were used. They have mineral insulating composite magnesium oxide positioned at six points on the inner surface of the tube.

The measurement uncertainty was obtained from the uncertainties related to thermocouple measurement position shifts in the temperature of the transducer (data collector) and sensor itself (Type K thermocouple). The expanded uncertainty was $\pm 10.4^{\circ} \mathrm{C}$ at the $95 \%$ confidence level. In the following figures are presented the experimental temperature profiles of the test tube, while in all profiles observed an exponential decrease in temperature is expected.

Figure 7 refers to thermocouples in Position 1 in the end opposite the entrance of the shed heat treatment. It presents an exponential decrease of the average temperature in the section as expected.

Figure 8, related to thermocouples in Position 2 and located approximately in the middle of the tube, has an exponential decrease of the average temperature in the section as expected. 


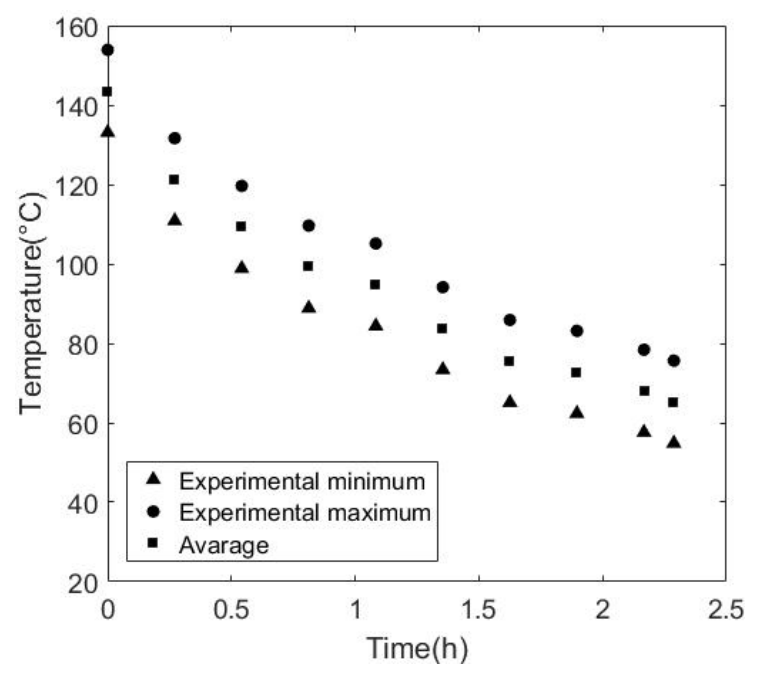

Figure 7. Experimental results with measurement uncertainty - position 1 (Fig. 6).

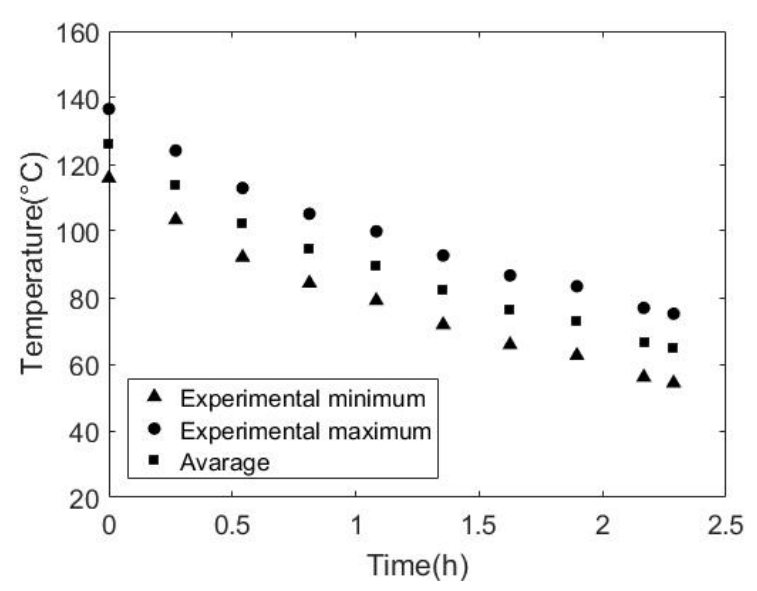

Figure 8. Experimental results with measurement uncertainty - Position 2 (Fig. 6) x numerical result.

Figure 9 refers to the thermocouples in Position 3 near the inlet of the heat treatment shed. This figure presents an exponential decrease of the average temperature in the section as expected.

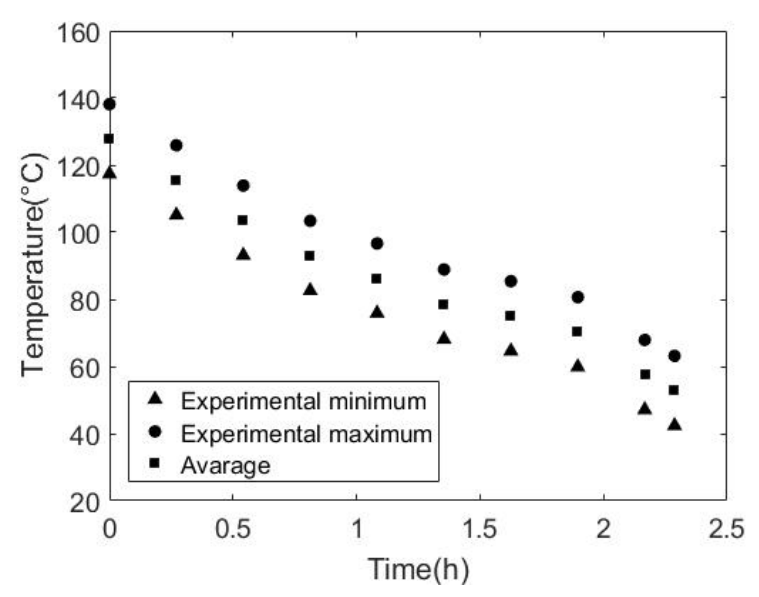

Figure 9. Experimental results with measurement uncertainty. - Position 3 (Fig. 6) x numerical result.

\section{CONCLUSIONS}

This work is developed in an experimental pipe cooling process using a continuous bed, subjected to heat loss by natural convection and radiation. The cooling bed is part of one of the stages of the heat treatment process of tempering industrial steel. The bed used is composed of two sections with different behaviors. In the first part of the bed, heat loss occurs by mixed convection and radiation, whereas in the second portion of the bed it only results from natural convection and radiation. Surveying the experimental data has not been possible without paralyzing the pipe production line. Because of these minor factors, strategies were prepared in a simplified way to survey the temperatures at particular points along the tube and the temperature of the surroundings.

The experimental obtaining of temperatures during the steelmaking process is a difficult and expensive task, as it requires the use of devices with sophisticated measuring systems installed on steel equipment production lines in full operation. Thus, the difficulty of obtaining repeatability of measurements under the same conditions and the high degree of complexity to obtain sources of uncertainty inherent in the process are factors that influence the final result of the temperature measurement. These experimental measurements presented in this paper are intended to validate the mathematical model presented by Souza (2007).

The experimental temperature profiles obtained during the cooling process showed a $10.4^{\circ} \mathrm{C}$ uncertainty. The temperature gradient was greater in the end nearest the shed entrance compared to the opposite end, because of the influence of room temperature. There was an exponential decrease in all experimental temperature profiles of the test tube as expected.

\section{ACKNOWLEDGEMENTS}

The authors appreciate the support of CAPES, CNPq, and FAPEMIG. This study also was supported by Vallourec steel company located in Belo Horizonte, Brazil.

\section{REFERENCES}

Abdulkadir, M., Hernandez-Perez, V., Lo, S., Lowndes, I. S., and Azzopardi, B. J., 2015, Comparison of Experimental and Computational Fluid Dynamics (CFD) Studies of Slug Flow in a Vertical Riser, Experimental Thermal and Fluid Science, Vol. 68, pp. 468-483.

Agrawal, C., Kumar, R., Gupta, A., and Chatterjee, B., 2012, Effect of Jet Diameter on The Rewetting of Hot Horizontal Surfaces During Quenching,Experimental Thermal and Fluid Science, Vol. 42, pp. 25-37.

Damasceno, J., 2004, Modelagem Física em 
Escala Real do Processo de Resfriamento de Tubos Durante o Revenimento na Linha da Vallourec \& Mannesmann Tubes, Master Thesis, Universidade Federal de Minas Gerais, Belo Horizonte, MG. (in Portuguese)

Davies, M. A., Ueda, T., M'saoubi, R., Mullany, B., and Cooke, A. L., 2007, On The Measurement of Temperature in Material Removal Processes. CIRP annals, Vol. 56, pp. 581-604.

De Souza, J. L. F., 2007, Modelagem Matemática do Resfriamento de Tubos em Leito Contínuo, Doctoral Thesis, Universidade Federal de Minas Gerais, Belo Horizonte, MG. (in Portuguese)

Dixon, A. G., Walls, G., Stanness, H., Nijemeisland, M., and Stitt, E. H., 2012, Experimental Validation of High Reynolds Number CFD Simulations of Heat Transfer in a Pilot-Scale Fixed Bed Tube, Chemical Engineering Journal, Vol. 200, pp.344-356.

Figliola, R. S., and Beasley, D., 2015, Theory and Design for Mechanical Measurements, John Wiley \& Sons.

Hashmi, M. S. J., 2006, Aspects of Tube and Pipe Manufacturing Processes: Meter to Nanometer Diameter, Journal of Materials Processing Technology, Vol. 179, pp. 5-10.

Hu, D., Liu, P., Zhao, W., Zhu, C., Wang, Y., Dai, Y., and Zou, J., 2009, Study on Wall Temperature Distribution of Oscillating Tube, Journal of Thermal Science, Vol.18, pp. 246-252.

Karwa, N., Gambaryan-Roisman, T., Stephan, P., and Tropea, C., 2011, Experimental Investigation of Circular Free-Surface Jet Impingement Quenching: Transient Hydrodynamics and Heat Transfer, Experimental Thermal and Fluid Science, Vol. 35, pp. 1435-1443.

Lin, M., Wang, Q. W., and Guo, Z. X., 2012, A Simple Method for Predicting Bulk Temperature from Tube Wall Temperature with Uniform Outside wall Heat Flux, International Communications in Heat and Mass Transfer, Vol. 39, pp. 582-586.

Rezvantalab, H., Ghazian, O., Yousefi, T., and Ashjaee, M., 2011, Effect of Flow Diverters on Free Convection Heat Transfer from a Pair of Vertical Arrays of Isothermal Cylinders, Experimental Thermal and Fluid Science, Vol. 35, pp. 1398-1408.

Roberts, I. L., Coney, J. E. R., and Gibbs, B. M., 2011, Estimation of Radiation Losses from Sheathed Thermocouples, Applied Thermal Engineering, Vol. 31, pp. 2262-2270.

Shabanian, S. R., Rahimi, M., Shahhosseini, M., and Alsairafi, A. A., 2011, CFD And Experimental Studies on Heat Transfer Enhancement in an Air Cooler Equipped with Different Tube Inserts, International Communications in Heat and Mass Transfer, Vol. 38, pp. 383-390.

Shen, Z., Yang, D., Chen, G., and Xiao, F., 2014, Experimental Investigation on Heat Transfer Characteristics of Smooth Tube with Downward Flow, International Journal of Heat and Mass
Transfer, Vol. 68, pp. 669-676.

Souza, J. L. F., Ziviani, M., and Vitor, J. F. A., 2015, Mathematical Modeling of Tube Cooling in a Continuous Bed, Applied Thermal Engineering, Vol. 89, pp. 80-89.

Yoon, J. I., Phan, T. T., Moon, C. G., Lee, H. S., and Jeong, S. K., 2008, Heat and Mass Transfer Characteristics of a Horizontal Tube Falling Film Absorber with Small Diameter Tubes, Heat and Mass Transfer, Vol. 44, pp. 437-444.

Yousefi, T., and Ashjaee, M., 2007, Experimental Study of Natural Convection Heat Transfer From Vertical Array of Isothermal Horizontal Elliptic Cylinders, Experimental Thermal and Fluid Science, Vol. 32, pp. 240-248.

Zhao, C. R., and Jiang, P. X., 2011, Experimental Study of In-Tube Cooling Heat Transfer and Pressure Drop Characteristics of R134a at Supercritical Pressures, Experimental Thermal and Fluid Science, Vol. 35, pp. 1293-1303. 